\title{
CONFLICTOS AMBIENTALES DERIVADOS DE LA URBANIZACIÓN TURÍSTICO-RESIDENCIAL. UN CASO APLICADO AL LITORAL ALICANTINO*
}

\author{
Margarita Capdepón Frías \\ Departamento de Turismo. Universidad Católica de Murcia \\ mcapdepon@ucam.edu
}

\section{RESUMEN}

La actividad turística desarrollada en el Mediterráneo español, en general, y en el litoral valenciano, en particular, está vinculada a la demanda de segundas residencias y, con ella, al desarrollo urbanístico. Se trata de un modelo que incide negativamente sobre el territorio y genera fuertes impactos, especialmente medioambientales, apenas frenados por las medidas conservacionistas llevadas a cabo en las últimas décadas. Para comprobar tales afirmaciones, el presente artículo se centra en un territorio concreto como el litoral de la provincia de Alicante, donde los parques naturales mantienen una estrecha relación con algunos de los principales destinos de sol y playa.

Palabras clave: parque natural, conservación de la naturaleza, plan general de ordenación urbana, presión urbanística, turismo residencial.

Fecha de recepción: abril 2014.

Fecha de aceptación: marzo 2015.

* El trabajo resulta de la tesis doctoral El papel de los parques naturales como elementos de diversificación en el marco de la renovación de los destinos turísticos consolidados, realizada merced a una ayuda FPI (BES-2009014684) del Ministerio de Economía y Competitividad, asociada al proyecto Renovación de los destinos turísticos consolidados del litoral: nuevos instrumentos para la planificación y gestión (RENOVESTUR) (CSO2008-00613). El proyecto, cuyo investigador principal es también el director de la tesis, el Dr. J. Fernando Vera Rebollo, fue desarrollado en el Instituto Universitario de Investigaciones Turísticas de la Universidad de Alicante, financiado por el Plan Nacional I+D+I 2008-2011 del Ministerio de Ciencia e Innovación. 


\section{ABSTRACT}

The tourist activity developed in the Spanish Mediterranean sea as a whole and particularly in the coast of the Valencian Autonomous Region is closely linked to the demand for second homes and, consequently, to urban development. This model has negative effects on the territory and generates strong impacts, especially from an environmental point of view, barely controlled by the conservationists measures implemented for the last decades. To verify these statements, the present work is focused on a specific territory as the Alicante Province coastline, where natural parks have a close relationship with many of the most important coastal tourism destinations.

Keywords: natural park, conservation of nature, general urban land-use plan, urban pressure, residential tourism.

\section{INTRODUCCIÓN}

Bien es sabido que existe una tendencia creciente de las sociedades contemporáneas a residir en las ciudades, hasta el punto que principios del presente siglo, y por primera vez en la historia de la Humanidad, la población urbana ha superado a la rural; y parece que puede alcanzar las dos terceras partes del total mundial a mediados de siglo (ONU, 2014:7). Las ciudades se han convertido en reflejos de un modelo de desarrollo económico contrario a los imperativos ambientales (Pellicer, 2001:364; Gaja, 2008a:114) y han experimentado un «explosivo crecimiento periférico» (Fernández García, 2003:89) como resultado de las nuevas tecnologías de la información y comunicación (TIC), la desconcentración productiva y la terciarización de la economía, acelerada sobre las bases del comercio, los trasportes y el turismo. Un crecimiento en el que también han incidido factores sociales a partir de la nueva movilidad individual, impulsada por el uso del vehículo privado, y de la independencia personal y la flexibilidad de las relaciones sociales favorecidas por las mismas TIC (teléfono móvil, conexión wifi, Internet, ordenador personal, etc.). Así, se ha ido configurando una nueva organización territorial distinta a la ciudad compacta tradicional (Fernández García, 2003:90; Ponce, 2006:111) en la que los espacios urbanos, también los turísticos, ya no crecen de forma continuada como si de una mancha de aceite se tratara.

Como explica López de Lucio (1993:11) asistimos desde hace unas décadas a la desaparición de la ciudad clásica en favor de unos espacios urbanos menos densos, menos compactos

y de límites más indefinidos. Se ha producido una ocupación dispersa del suelo urbano que provoca la fragmentación de la ciudad y la pérdida de su imagen convencional, algo que, por otro lado, estimula una mayor movilidad tanto de personas como de medios de transporte. Y al extender sus funciones fuera de los límites tradicionales mediante la ocupación desordenada de los espacios circundantes, la ciudad invade sus entornos naturales donde causa enormes impactos ambientales.

Se trata de una expansión urbana descontrolada (conocida como urban sprawl o sprawl urbano) y un aumento de la movilidad espacial que se extienden rápidamente en todo el mundo. Fenómenos globales que en la Europa mediterránea, y particularmente en países como España, se materializan con un continuo e intenso incremento del número de viviendas 
y segundas residencias motivada por el crecimiento económico y el turismo (EEA, 2006:23; MMA, 2008:23). Un sector este último que, en el ámbito territorial en cuestión, mantiene estrechos vínculos con la construcción y la promoción inmobiliaria en lo que se conoce como turismo residencial. Con todo, y pese a la generalización del término, cabe tener en cuenta que es un concepto ciertamente contradictorio ya que por su principal característica (la residencia) no debería ser considerado como turismo en la mayoría de los casos; máxime cuando se trata de una actividad que suele salir al mercado fuera de los canales reglados. Es una visión compartida por muchos autores (Anton, 2004: 317; Mazón y Aledo, 2005:13; Artigues y Rullán, 2007; Díaz y Lourés, 2008:85; Huete, Mantecón y Mazón, 2008:103; Obiol y Pitarch, 2011:179; Pulido, 2011:41) para quienes ese turismo residencial se encontraría más próximo al sector inmobiliario que a la propia actividad turística, en lo que Vera y Marchena (1996:329) concluyeron en llamar la «instrumentación inmobiliaria del turismo».

Más allá de cuestiones puramente conceptuales, de lo que no cabe ninguna duda es que se trata de un modelo de desarrollo que genera unos enormes impactos medioambientales en los primeros kilómetros de litoral y cada vez más hacia el interior. Circunstancia que, aparte de las motivaciones conservacionistas stricto sensu (Delgado, 2008:278), ha incrementado todavía más la necesidad de proteger determinados sectores del territorio de alto valor natural que se encuentran fuertemente amenazadas por tal presión urbano-turística.

\section{OBJETIVO Y METODOLOGÍA}

Con la intención de profundizar en estas cuestiones, el presente trabajo tiene como principal objetivo realizar una exhaustiva investigación de base empírica desde la escala local, con particular atención a las implicaciones territoriales ocasionadas por la compleja relación entre la actividad turístico-recreativa, el desarrollo inmobiliario asociado, y la conservación de la naturaleza. Para ello, se ha optado por plantear dos estudios de caso localizados en el litoral de la provincia de Alicante como ejemplos representativos, aunque no los únicos, de la realidad que se pretende conocer. Con ellos, se lleva a cabo un análisis descriptivoexplicativo de dos ámbitos territoriales concretos en los que coexisten un parque natural y un destino turístico litoral. Son:

- El Parque Natural del Montgó (2093 ha), un gran relieve litoral de 750 m de altura extendido casi de forma paralela a la costa entre los municipios turísticos de Dénia y Jávea, que son estudiados en profundidad.

- El Parque Natural de las Lagunas de la Mata y Torrevieja (3743 ha), un conjunto lagunar formado por dos láminas de agua que se extienden entre los municipios de Torrevieja, Guardamar del Segura, Rojales y Los Montesinos. De todos ellos, se analizará con mayor detalle el primero.

Tras hacer una breve presentación de ambos parques y resaltar sus principales valores, el trabajo se centra en el papel que estos han desempeñado en los municipios de su entorno, en particular de aquellos con una mayor trayectoria turística. Tanto Dénia y Jávea, en el primer caso, como Torrevieja, en el segundo, son destinos adscritos al modelo de sol y playa masivo que han alcanzado un elevado grado de consolidación en su ciclo de vida. En este contexto, 
se remarcan los efectos negativos ocasionados por el crecimiento urbano en el medio natural, incluso después de ser declarados los parques naturales. Para ello, se ha revisado de manera muy especial la evolución del planeamiento urbanístico a través de los Planes Generales de Ordenación Urbana (en adelante, PGOU) de cada municipio desde la llegada del turismo de masas hasta la actualidad. Un largo periodo con ciclos de enorme crecimiento urbanístico como el acontecido entre mediados de los años noventa y el estallido de la actual crisis económica; un último auge inmobiliario que recibe una atención específica en el análisis empírico.

Por último, es preciso llamar la atención acerca del gran protagonismo que tiene en la segunda parte del trabajo la escala local, pues constituye el nivel en el que se producen las interrelaciones entre parque natural y espacio urbano-turístico. No en vano, y de acuerdo con Baños (1999:36),

«esta es la escala más apropiada para el análisis de los destinos turísticos adscritos al modelo de sol y playa masivo debido a la importancia que en la configuración de los mismos han tenido las estructuras preturísticas locales, los agentes económicos actuantes y el marco jurídico administrativo que otorga, en el caso español, al municipio importantes competencias en materia de planeamiento urbanístico».

\section{EL PAPEL DEL TURISMO RESIDENCIAL EN EL CRECIMIENTO URBANO DEL LITORAL MEDITERRÁNEO ESPAÑOL}

Como se ha avanzado anteriormente, la expansión urbana no se ha producido de manera homogénea en el territorio español sino que se concentra en determinados sectores como el área metropolitana de Madrid, algunas ciudades medias y, de manera particular, a lo largo de la franja litoral, donde se ha convertido en un fenómeno «endémico» (EEA, 2006:31). Y es que durante la segunda mitad del siglo pasado buena parte de la población española, así como las actividades socioeconómicas, se fueron desplazando hacia las zonas costeras, y en especial hacia las regiones mediterráneas (Almenar, Bono y García, 2000:84; OSE, 2006:156; MMA, 2008:23; Santos y Fernández, 2010:197) y los espacios litorales de vocación turística (Romero, 2010:29), promovidas por sus atributos climáticos, territoriales y culturales (Perelli, 2011:53).

Una litorización del territorio que se explica en gran medida por el efecto arrastre del desarrollo turístico de nuestro país desde los años sesenta, y en concreto por la prevalencia de la dimensión residencial, que no ha dejado de crecer en las últimas décadas y que ha tenido momentos de extraordinarios impulsos. El último de ellos ha coincidido en España con un periodo de enorme bonanza económica que comienza a mediados de los noventa y que dio a lugar a un desarrollo urbanístico desorbitado que habría producido más de la tercera parte del suelo urbano existente en nuestro país (OSE, 2006:32; Romero, 2010:26), así como el mayor crecimiento urbano de muchas zonas del litoral en toda su historia (Mata, 2007:7). Este boom constructor se acelera todavía más durante los primeros años del presente siglo, una etapa en la que, de acuerdo con los datos ofrecidos por Prieto, Campillo y Díaz (2011:265) para el periodo 2000-2005, España experimenta un incremento de superficies urbanas e infraestructuras de unas 27000 ha anuales o, lo que es lo mismo, unas 3 ha a la hora. Evidencias todas ellas que han llevado a Burriel (2008) a hablar de la «década prodigiosa» del urbanismo 
español y a distintos autores a calificar el fenómeno como «tsunami urbanizador» (Fernández Durán, 2006; Gaja, 2008b), «tsunami urbanístico» (García Bellido, 2005; Gaja, 2005) o «urbanismo salvaje» (Delgado, 2008:273). Una «máquina de crecimiento» (Díaz, 2004:126) a la que solo el comienzo de la crisis en el año 2007 y el posterior estallido de la burbuja inmobiliaria han sido capaces de poner freno.

La preocupante evolución experimentada por los usos del suelo en España durante esos años hizo que en 2006 numerosos investigadores y colectivos profesionales ${ }^{2}$ previnieran de las graves consecuencias que la urbanización masiva podía traer, a través del conocido como Manifiesto por una nueva cultura del territorio. Años más tarde, y en un contexto socioeconómico radicalmente diferente en el que el sector de la construcción está sufriendo los efectos de una profunda crisis, muchos de estos mismos investigadores, junto con otros, vuelven a mostrar públicamente su preocupación ${ }^{3}$. En esta ocasión ante las modificaciones planteadas por el gobierno español en la Ley de Costas de 1988, con las que se pretende reactivar los usos en el litoral o ampliar las concesiones de la propiedad en el dominio público marítimoterrestre. De prosperar, dice el Manifiesto por la preservación y gestión de los espacios costeros, «afectaría muy negativamente al conjunto del litoral español y en especial a las áreas costeras que aún conservan valores naturales destacados (...) y produciría una significativa pérdida en términos económicos y de calidad ambiental para residentes y visitantes».

Uno impactos que, a menudo, ni siquiera son minimizados por las medidas conservacionistas llevadas a cabo por las Administraciones públicas como se comprueba con el número de espacios naturales protegidos (en adelante, ENP) que se encuentran sometidos a un creciente «acoso urbanístico» (Delgado, 2008) y el empuje de la especulación inmobiliaria (Blázquez, 2007). El tsunami urbanizador arrasa con todo al tiempo que la declaración de espacios protegido no es garantía de supervivencia, máxime si no se aplican los instrumentos de gestión adecuados. En ocasiones, incluso, son los propios organismos y gobiernos autonómicos, encargados de velar por la conservación de los espacios protegidos, quienes modifican límites y revisan normativas (Ecologistas en Acción, 2007:17; Delgado, 2012:626), muchas veces «bajo la máscara del turismo» (Blázquez, 2007). Así, el desarrollo de la construcción, además de grandes infraestructuras, campos de golf, centros de ocio o puertos deportivos, ha provocado fuertes impactos en la red de espacios protegidos, a pesar de que por principio legal no deberían ser urbanizables (Delgado, 2008:273).

Incluso muchos ENP se están convirtiendo en focos de atracción para la llegada de nueva población residente, en lo que algunos autores han denominado como procesos de «naturbanización» (Prados, 2006:90). Y es que a la presencia de valores naturales en los espacios protegidos del litoral y/o próximos a áreas urbanas se une a la benignidad de las condiciones climáticas, la presencia del mar y las playas como reclamos que derivan en un incremento demográfico en estas áreas, condicionadas, además, por una estructura económica más diversificada y una importante intensificación de la agricultura intensiva (Prados, 2006:104-105). Un fenómeno que, sin duda alguna, aumenta la presión sobre estos espacios, así como la posibilidad de generar impactos negativos.

\footnotetext{
1 Citado en Gaja (2008b).

2 «108 expertos en urbanismo piden que se controle la masificación». Diario El País, 08/05/2006.

3 Romero, J. et. al «En defensa de nuestra costa». Diario El País, 12/07/2012.
} 


\section{LA CONSERVACIÓN DE LA NATURALEZA COMO FRENO A LA OCUPACIÓN URBANO- TURÍSTICA DEL TERRITORIO. EL CASO VALENCIANO}

No cabe duda que el desarrollo turístico basado en la promoción y construcción de alojamiento y orientado a la demanda se ha convertido en uno de los verdaderos pilares de crecimiento económico en la Comunidad Valenciana desde los años sesenta. Sin embargo, no es menos cierto que lo hace de la mano de un modelo basado en un turismo masivo de sol y playa y una marcada vertiente residencialista en el alojamiento que, como ya se ha dicho, provoca enormes impactos negativos sobre el medio ambiente y el territorio.

Sin ir más lejos, las primeras actuaciones en materia conservacionista llevadas a cabo a mediados de los años ochenta surgen en buena medida como respuesta ante la creciente presión ejercida por la ocupación urbano-turística. El gobierno valenciano centra su interés en preservar pequeños reductos de gran valor ecológico (Vera y Baños, 2001:387) de los ecosistemas valencianos, y de manera muy particular los humedales costeros; unos espacios que habían sufrido una histórica transformación para el aprovechamiento agrícola y, más recientemente, la presión de las actividades (industriales, urbanas y turísticas) y la concentración de la población en el litoral.

Es a partir de ese momento cuando se crean los primeros ENP al amparo de la ley (estatal) de 1975, y se aprueban las primeras leyes conservacionistas de ámbito estrictamente autonómico. Con la Ley de Parajes Naturales de 1988 se protegen varios espacios lacustres que se encontraban fuertemente amenazados. Poco después, y en un contexto marcado ya por el paradigma del desarrollo sostenible, se redacta la Ley de Espacios Naturales Protegidos de la Comunidad Valenciana de 1994, todavía vigente en la actualidad. Cabe subrayar que el propio documento ya advertía en su preámbulo acerca de la existencia de «ciertos sectores del territorio, en buena parte costeros, [que] sufren un proceso de desarrollo acelerado en términos económicos, poblacionales y de uso del territorio, lo que somete a los ambientes naturales a una presión muchas veces excesiva. Se da la circunstancia de que estos ambientes costeros son los más frágiles y ricos en cuanto a diversidad de especies y paisajes».

Dicho de otro modo, la declaración de los primeros ENP de la Comunidad Valenciana, en su mayoría parques naturales, fueron unas «verdaderas operaciones de salvamento» (Cruz y Such, 2001:557) centradas en aquellos espacios naturales localizados en los primeros kilómetros de costa que durante años se han visto amenazados por un proceso de urbanización altamente consumidor del suelo. Con todo, fueron unas declaraciones que para muchos llegaron demasiado tarde y no fueron capaces de evitar la enorme pérdida de patrimonio natural, así como los costes ambientales y paisajísticos asociados (Ors y Viñals, 1995:299; Cruz y Such, 2001:563). De ahí también que buena parte de los parques naturales del litoral valencianos limiten con importantes destinos turísticos en los que actúan como «espacios de trinchera, verdes, abiertos y de uso público» (Obiol y Pitarch, 2011:196), pero también que se encuentren sometidos ante una presión antrópica constante. Y todavía más durante el último auge inmobiliario.

La Comunidad Valenciana presenta desde los años noventa uno de los crecimientos de superficie artificial más elevados del país (OSE, 2006:338; Delgado, 2012:618), donde destaca especialmente la provincia de Alicante, cuyos primeros kilómetros de costa han experimentado la mayor transformación de suelo de toda España (Martí y Nolasco, 2011:369). 
En este sentido, cabe subrayar que únicamente en los sesenta municipios litorales, los cuales abarcan el 14\% de la superficie de la Comunidad Valenciana, viven más de 2,7 millones de habitantes, el 53\% de la población total; porcentaje que asciende hasta el $80 \%$ si se considera la cota de $100 \mathrm{~m}$ de altitud sobre el nivel del mar. Esos mismos términos municipales presentan una densidad media de unos de $825 \mathrm{hab} / \mathrm{km}^{2}$, que supera con facilidad los $1000 \mathrm{hab} / \mathrm{km}^{2}$ durante los meses de verano. Por datos como estos hay quien afirma que la construcción de segundas residencias es, precisamente, el hecho principal que pone en duda la compatibilidad del fomento turístico con la conservación de la naturaleza (Hernández, 2008:95).

\section{EL ANÁLISIS DE LAS RELACIONES DESDE LA ESCALA LOCAL. LA CRECIENTE PRESIÓN SOBRE LOS ESPACIOS NATURALES DEL LITORAL ALICANTINO}

Hasta la llegada del turismo de masas a finales de los años cincuenta del siglo pasado, los pueblos costeros valencianos se dedicaban casi en exclusiva a la pesca, la agricultura y otros aprovechamientos tradicionales, al tiempo que la actividad preturística presentaba una reducida significación económica y una escasa incidencia sobre el territorio. Es en ese momento cuando un incipiente turismo de masas se convierte en el gran dinamizador socioeconómico y motiva el comienzo de un constante crecimiento urbano y demográfico que, con periodos de mayor y menor intensidad, ha supuesto una completa transformación, tanto desde una perspectiva socioeconómica como territorial.

En consecuencia, buena parte de los enclaves survalencianos de mayor valor natural se han visto sometidos desde entonces a los crecientes efectos generados por el desarrollo de los principales centros turísticos del litoral, presión controlada por el planeamiento urbanístico y escasamente frenada por las medidas en materia conservacionista llevadas a cabo durante estas últimas décadas. Así al menos se comprueba con los dos casos expuestos a continuación.

\section{V.1. El Parque Natural del Montgó: un enclave de singular localización}

El Parque Natural del Montgó (2093 ha) es una montaña litoral de unos 750 m de altitud que discurre casi paralela al mar, con el que enlaza a través de la llanura de Les Planes y el Cabo de San Antonio, en una zona de transición entre un clima marcado por un periodo de acusada sequía y otro de elevada pluviometría. La flora es uno de los elementos más representativos y una de las razones que motivaron la protección del enclave en 1987, en un ámbito donde la abrupta topografía, la composición de sus suelos, la proximidad del mar, la diversidad ombroclimática, y las actividades humanas contribuyen a la existencia de una gran variedad de especies y numerosos endemismos. La fauna, por su parte, está ligada a las unidades paisajísticas y comunidades vegetales, y presenta una especial riqueza desde el punto de vista avifaunístico.

Los restos hallados evidencian asentamientos humanos de hace unos ciento veinte mil años y, desde entonces, se ha producido una continua ocupación del territorio. Hasta hace unas décadas, el Montgó era una pieza clave en el impulso de las poblaciones como soporte para la agricultura, principal base económica, y las terrazas de cultivo, dedicadas particularmente a la vid, se extendían por las laderas configurando el paisaje propio de este relieve. 
La irrupción del turismo de masas a mediados del siglo pasado y el cambio de modelo en la ocupación del suelo provocaron una fuerte transformación socioeconómica, medioambiental y paisajística. No en vano, como se comprueba en la siguiente figura, se trata de un «límite natural» (Cruz, Donat y Rodríguez, 2002:240) entre Dénia y Jávea, dos destinos que han experimentado una intensa actividad turístico-inmobiliaria.

De acuerdo con Fernández Muñoz (2003:43), analizados los planeamientos urbanísticos de ambos municipios, se puede decir que la práctica totalidad del perímetro del parque natural ha estado en contacto con áreas urbanas consolidadas o zonas donde el planeamiento permitía la edificación. Tanto es así que la nueva delimitación presentada en 1997 dejaría fuera de la zona protegida el suelo urbano consolidado creado sobre la base de varios planes parciales (Cervera et al., 2013:80), por lo que la definición del espacio protegido se ha visto condicionado por la titularidad de los terrenos y la clasificación del suelo, más que por criterios físicos o naturales (Such, 1995:111). De ahí los problemas de delimitación, que sus irregulares lindes conecten directamente con las zonas residenciales y que incluso lleguen a discurrir entre ellas (Cruz, Donat y Rodríguez, 2002:241), al tiempo que los relieves más escarpados permanecen como una «isla natural envuelta de urbanizaciones» (Ripoll, 2009:78).

\section{V.1.1. Dénia, capital comarcal y gran centro receptor de turistas y residentes}

A principios de los años sesenta, Dénia comienza a constituirse como núcleo de inmigración (Cruz, Donat y Rodríguez, 2002:240) y para mediados de década, su litoral ya estaba prácticamente ocupado por actuaciones turísticas que aprovechaban la debilidad del entorno institucional (Ripoll, 2009:36) y la ausencia de un planeamiento previo. La saturación en la costa explica la temprana ocupación de las tierras de interior y la extensión de la función turístico-residencial hacia las laderas montañosas prelitorales, entre ellas las del Montgó, expuesto, desde siempre, a los efectos y presiones derivados de la mano del hombre (Cervera et al., 2013:77). Para Ripoll (2009:47) los constructores encontraron allí un auténtica «mina de oro» pues eran zonas de escaso valor agrícola, en pendiente, con un parcelario mucho más grande y a un precio inferior. Se sientan así las bases de un modelo de ocupación caracterizado por la hegemonía de la baja densidad que provocaría una evidente degradación ambiental y paisajística (Vera, 1987:172).

Tras un periodo «de actuaciones incontroladas [y] una absoluta permisividad de la administración actuante» (Vera, 1987:305), se aprueba el primer PGOU en 1972. Con él, se declara Suelo Rústico de Interés Turístico (en adelante, SRIT) parte del Montgó, donde se permite la urbanización incluso sin planeamiento, y se califica el resto del macizo como Suelo Rústico Forestal, en el que también se podían llevar a cabo intervenciones con planeamiento previo, pero en ausencia de aspectos relacionados con la protección ambiental (Vera, 1987:306). Se trata de una dimensión edificatoria que, de acuerdo con Navalón (1995:90), «no deja de sorprender (...) dado el interés ecológico y paisajístico de este enclave que le valió la declaración de parque natural». Así, a través de planes parciales, se acomete la ocupación de varios sectores de la ladera norte del Montgó con conjuntos de viviendas aisladas (San Juan, Galeretes, Troyes, Marquesas), que, por lo general, seguían las directrices marcadas por el territorio (Martí y Nolasco, 2011:373). La lejanía de las aglomeraciones, la tranquilidad, y la singularidad del patrimonio natural y el paisaje fueron factores determinantes 


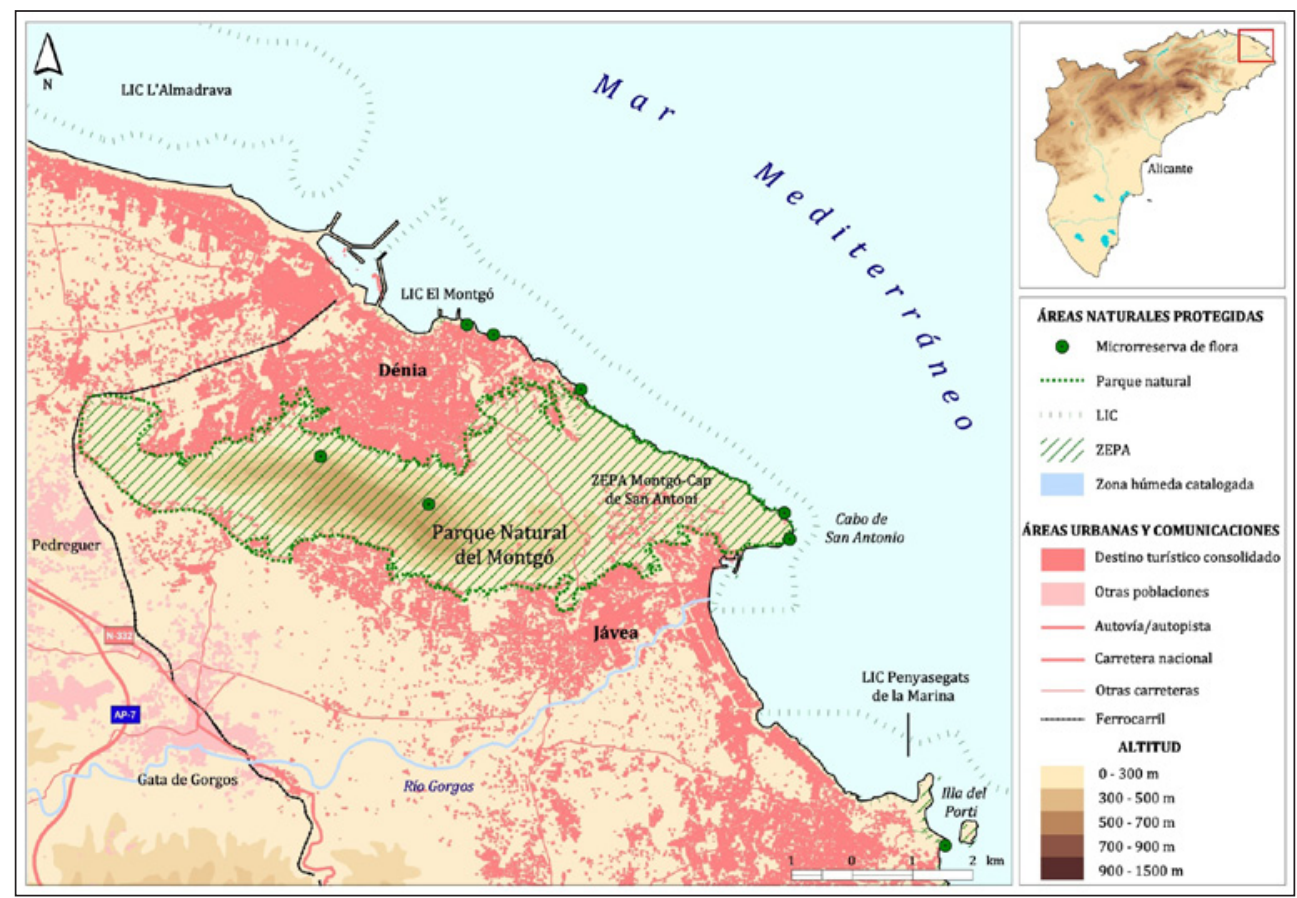

Fuente: elaboración propia a partir de la base cartográfica del Terrasit.

para que un gran número de residentes, en su mayoría centroeuropeos, se fueran asentando en este entorno, en ocasiones mediante la ocupación de pequeñas parcelas de cultivo abandonadas y que ahora se revalorizaban de nuevo.

Llegado este punto, las autoridades se ven obligadas a modificar los documentos de planificación debido a la destrucción del medio, la degradación paisajística, la creciente congestión y las deficiencias en infraestructuras básicas, de manera que se inician los trabajos para la revisión del PGOU, que no sería finalmente aprobado hasta el año 1990. Es un periodo que coincide, además, con la declaración del Parque Natural del Montgó (1987), que «supuso un importante freno a las expectativas urbanísticas en este espacio natural» (VV.AA., 1990:79). El propio texto declaratorio advertía de los efectos negativos provocados por el modelo de desarrollo y señalaba que «las agresiones a los ecosistemas y al paisaje del Montgó se [habían] incrementado en los últimos tiempos a consecuencia de su situación en un área con fuerte dinámica de crecimiento turístico».

De manera que el plan de 1990 pretendía establecer las medidas oportunas para la conservación del medio ambiente, entre ellas frenar la expansión del diseminado. Sin embargo, permitía edificar con vivienda aislada y de uso turístico-residencial o de interés público social en algunas partes del Montgó, en cuyas laderas se incrementaba aún más el pobla- 
miento disperso (Antolín, 1990:97) y la función turística; en otras palabras, el planteamiento urbanístico mostraba una clara contradicción. Y todo ello, según explican Martí y Nolasco (2011:373), en el marco de un cambio en la ocupación territorial de la Marina Alta por el que se empieza a generar un nuevo suelo artificializado de gran impacto visual, nada acorde con la orografía, se proyectan nuevas parcelas reducidas y absolutamente inconexas para la edificación de viviendas unifamiliares o adosadas, y se crean hileras de viviendas alineadas a viario a modo de nuevas «murallas territoriales». En los espacios más próximos al ya parque natural, el tratamiento urbanístico no preveía zonas verdes que actuaran de colchón amortiguador entre las áreas urbanas y el espacio protegido, lo que contribuyó a agravar la presión urbanística sobre este (Fernández Muñoz, 2003:43).

Además, es preciso llamar la atención acerca de que el Plan General de 1990 experimentaría un largo y complejo proceso que se inicia con la anulación por parte del TSJCV en 1994 de su aprobación inicial, refrendada por el TS en 2000. Por ello, junto con las numerosas modificaciones incorporadas hasta entonces, es sometido a información pública para ser aprobado provisionalmente en julio de 2000, y después definitivamente en septiembre de ese mismo año, aunque sería anulado de nuevo por el TSJCV en 2003. En relación a esta segunda suspensión, cabe subrayar que una de las razones radicaba, justamente, en el incumplimiento de la necesaria protección de elementos arqueológicos y recursos naturales como el Montgó. Finalmente, con el objetivo de solventar la situación de urgencia, el Ayuntamiento de Dénia aprueba el Plan General Transitorio (en adelante, PGT) del municipio en 2006, que se ha mantenido vigente hasta el año 2012.

Por su parte, el Parque Natural del Montgó no ve aprobado su Plan de Ordenación de los Recursos Naturales (en adelante, PORN) hasta 2002, es decir, quince años después haber sido declarado. Un dilatado proceso justificado por el «desarrollo urbanístico y la consecuente ocupación de (...) parte de las laderas (...) que circundan el espacio natural protegido», que deriva, a su vez, en una «conflictividad social y jurídica que ha llegado incluso a poner en peligro los objetivos de la propia declaración del Parque Natural». De hecho, según indica Fernández Muñoz (2003:42-43), el grave problema de la presión urbanística llevó a los redactores a considerar el mantenimiento de ciertos corredores libres de urbanización como requisito para asegurar los valores del parque y evitar que se convirtiese en una «isla en un mar de espacios urbanizados». De ahí que se tomaran nuevas medidas para adaptar el planeamiento urbano a las estipulaciones del espacio protegido y de su PORN, con el objetivo de reducir la presión (Ripoll, 2009:73). Así, el PGT de 2006, y el posterior Texto Refundido de 2007, muestran un «escrupuloso respeto» por las determinaciones legales derivadas de aquel y clasifican al parque como SNUP.

Con todo, ni la redacción del PORN ni las adaptaciones del planeamiento han conseguido que desaparecieran por completo las tensiones provocadas por el desarrollo turístico-inmobiliario. A las que ya se han señalado, hay que añadir las derivadas de la ampliación del campo de golf de la Sella (inaugurado en 1991), situado en el área de amortiguación de impactos del parque, que provocó la destrucción de unas 26 ha de terrenos agrícolas incluidos dentro de los límites del PORN ${ }^{4}$, o el proyecto de construcción de cuatro mil nuevas viviendas en la zona de Les Marines (Greenpeace, 2005:50). Sector donde, según el planeamiento y algunas

4 Mascarell, M.J. «El Consell autorizó ampliar el campo de golf de Dénia sin esperar a que el TSJ dijera si era legal», Diario Levante-emv, 26/3/2008. 
denuncias de los propios constructores, existían en esos años miles de edificaciones que carecían de alcantarillado, pavimentación y alumbrado público, y presentaban problemas serios de falta de saneamiento. En este sentido, son claras las palabras recogidas en la memoria informativa del nuevo PGOU de Dénia, redactado y tramitado pero todavía pendiente de aprobación, cuando hace referencia a que:

«La enorme ocupación de la ladera del Montgó, ocupada con ausencia de una planificación conjunta, y apoyada tradicionalmente en el trazado de antiguos caminos, y servidumbres de paso generadas por parcelaciones privadas, ausentes de ordenación urbanística han motivado la situación caótica de parcelación, accesos y ausencia de dotaciones, equipamientos y servicios, del entorno más privilegiado del parque natural».

Si bien se trata de una realidad que viene de mucho tiempo atrás, la magnitud de la presión ejercida por el crecimiento urbanístico sobre el Parque Natural del Montgó ha sido cada vez mayor. Máxime tras el ya mencionado periodo de extraordinario auge socioeconómico e inmobiliario que, motivado en parte por la actividad turística, fue muy intenso en zonas del litoral mediterráneo español entre 1996 y 2008. En esos años, se produjo en Dénia un considerable aumento de población del 160,3\% (según datos del INE) que reforzó todavía más el tradicional papel que el municipio, capital de la comarca de la Marina Alta, ha desempeñado como polo de atracción, y centro de infraestructuras y servicios. Conforme a los datos del Instituto Valenciano de Estadística (en adelante, IVE), igualmente sucede con el número de licencias de obra concedido durante dicho periodo para la construcción de más de 18.400 viviendas de nueva planta y que supuso la ocupación de unas 250 ha, en torno al 3,8\% del suelo municipal. La mayoría de estas viviendas han servido para seguir manteniendo el esquema urbano de baja densidad que caracteriza al municipio. Así, numerosos hogares unifamiliares y chalés se edificaron en las faldas del Montgó, al tiempo que se ocupaban parcelas libres de macrourbanizaciones como La Pedrera y El Montgó situadas en las laderas y en el sector de les Rotes, todas ellas dentro del PORN.

Por último, señalar que la situación actual del planeamiento urbanístico de Dénia viene marcada por un pronunciamiento judicial del TS en septiembre de 2012 por el que se anula el PGT de 2006, que no solo supuso su pérdida de vigencia sino también la reviviscencia del PGOU anterior, es decir, dada la cadena de anulaciones judiciales expuesta con anterioridad, el de 1972. De ahí, que el propio TSJCV reconociera su más que evidente obsolescencia, además de su inadaptabilidad a las necesidades actuales del municipio. En consecuencia, en mayo de 2013, se produce una suspensión de la vigencia de este PGOU y se establece un Régimen Urbanístico Transitorio aplicable hasta la aprobación definitiva de un nuevo planeamiento, actualmente en trámite, para el que se marca un plazo máximo de cuatro años.

\section{V.1.2. Jávea, descontrol urbanístico a pesar de un planeamiento temprano}

El inicio del desarrollo turístico de masas en los años sesenta en Jávea también se caracteriza por un fuerte impulso de la construcción a través de dos tipos de asentamientos fundamentales. Por un lado, con la edificación residencial en altura concentrada cerca de las 
Figura 2

EVOLUCIÓN URBANO-TURISTIICA DE DÉNIA, CON ESPECIAL INCIDENCIA EN EL MONTGÓ

ACONTECIMIENTO

Llegada turismo
de masas

revisión PGOU

Declaración PN Montgó

Nuevo PGOU

Anulación TSJCV

Anulación TS

Nueva aprobación

PGOU

PORN PN Montgó

Anulación PGOU por TSJCV

Aprobación PGT

Texto Refundido PGT

Último auge inmobiliario

Anulación PGT por TS

Suspensión PGOU y Régimen Urbanístico

Transitorio

\section{DÉNIA}

${ }^{\mathrm{a}}$ mitad

s. XX

$\mid$

Años

50

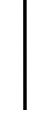

Años

6

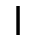$$
\text { servi }
$$

Colonia de extranjeros, invernantes y turistas en edificaciones veraniegas en el litoral

Asentamiento germano en

Revalorización del suelo y acelerado proceso de urbanización turística en la costa

Municipio como núcleo incipiente de inmigración interna y externa

Litoral ocupado por construcciones turísticas (edificios y bloques elevados)

Deficiencias de infraestructuras y servicios, y despreocupación por impactos

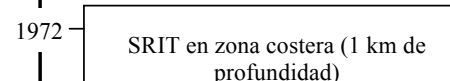
profundidad)

1981 Continuidad al desarrollo turístico-

I residencial y consolidación de la 1987 urbanización paralela al mar

1

1990- Importancia de la función turística como motor de avance económico 1994 1994
2000

Grandes urbanizaciones turísticas a lo largo de la costa

Crecimiento disperso (conversión de riu-raus en chalés) hacia las faldas del Montgó pequeños hoteles
।

1

\section{MONTGÓ}

Intento de colonización agrícola y reparto de tierras a colonos para la producción de uva de mesa.

Abandono de tierras improductivas

Zona de escaso valor agrícola, en pendiente, con gran parcelario

Ocupación de tierras interiores

Expansión de la función turísticoresidencial dispersa y de baja densidad (chalés) en las ladera a precio más bajo

Degradación ambiental y paisajística, y pérdida de la función agrícola

SRIT en una parte del Montgó y posterior urbanización en la zona montañosa.

Suelo Rústico Forestal en otra parte que permite actuaciones con planeamiento

Ocupación de ladera norte con conjuntos de viviendas aisladas (San Juan, Galeretes Troyes, Marquesas) que aprovechan parcelas de cultivo abandonadas

Medidas para la conservación y freno a la expansión del diseminado

SNUP en parcelaciones ordenadas y consolidadas

SNU en sectores no urbanizados de la ladera, y cerca de la cresta

Permisividad para las actuaciones de vivienda aislada y uso turístico-residencial

\begin{tabular}{c|c}
\hline 1 & $\begin{array}{c}\text { Incumplimiento de protección de } \\
\text { elementos arqueológicos y recursos }\end{array}$
\end{tabular}

I naturales (Montgó)

Nuevas medidas para adaptar el planeamiento urbano al PN y al PORN clasificado como SNUP

Mantenimiento del esquema urbano de baja densidad a partir de la yuxtaposición de conjuntos de viviendas unifamiliares.

Ocupación de parcelas libres por macrourbanizaciones (La Pedrera, El Montgó) en las faldas y sector de les Rotes (dentro del PORN)

Fuente: elaboración propia. 
playas y, por otro, con una ocupación dispersa del territorio a partir de acciones individuales, aisladas y anárquicas (Costa, 1977:530), a menudo sin permiso legal ni planeamiento previo. Ello explica la rápida congestión en la costa y el desbordamiento del fenómeno turísticoresidencial (Vera, 1987:175) hacia el resto del municipio, en especial en forma de viviendas unifamiliares que ocupan áreas montañosas de antigua función agrícola como las laderas meridionales del Montgó. La escasa antropización que presentaban en aquel momento, su alto valor ecológico y su elevada situación, los que permitía disponer de unas mejores condiciones paisajísticas, hacían de ellas las zonas más privilegiadas.

Con la intención de estructurar el modelo territorial futuro (Navalón, 1995:96) y establecer las pautas necesarias para un crecimiento ordenado, el municipio acomete la temprana redacción de su primer PGOU en 1965. Sin embargo, lejos de alcanzar tales objetivos, el planeamiento no hacía sino garantizar la posibilidad de seguir construyendo en todo el término municipal sobre la base de los principios del desarrollismo imperante (Such, 1995:164), y los intereses especulativos de la iniciativa privada. Además, como explica Vera (1987:312313), la administración local se ve incapaz de manejar las transformaciones generadas por la actividad turística en la población y el territorio, y muestra una absoluta permisividad ante el desmedido auge de la construcción. De este modo, se produce un desarrollo urbano incontrolado donde prolifera la baja densidad a partir de la construcción de chalés, a menudo ilegales (Montgó-Ermita, Bonavista, Montgó, Montesol) tanto en las faldas del Montgó como en el monte litoral, donde se mezclan con casas de campo preexistentes.

El PGOU clasificaba las laderas del Cabo de San Antonio como suelo residencial urbanizable por sus «favorables condiciones para la edificación de tipo residencial, con marcado carácter veraniego y turístico», de ahí que las mayores críticas se centraran no solo en la falta de control en el crecimiento urbano sino, además, en la contradicción en la que incurría el documento al contemplar la protección del paisaje natural al mismo tiempo que facilitaba la absorción de futuras ampliaciones del suelo residencial (Vera, 1987:313). Ya hacia finales de los años setenta, empiezan a incrementarse los conjuntos de chalés y bungalows (Vera, 1987:217), así como viejos rius-raus ${ }^{5}$ convertidos en chalés y grandes urbanizaciones turísticas (Antolín, 1990:97).

Ante dicho desorden, las autoridades locales llevan a cabo la adaptación y revisión del PGOU a finales de los ochenta, plan que es aprobado en 1990 y que, hasta la actualidad, sigue vigente. En él, tanto el Montgó como el Cabo de San Antonio, ambos incluidos dentro del ya declarado parque natural, quedan clasificados como SNUP de interés ecológicopaisajístico. El texto muestra un aparente cambio de actitud, ya que, entre sus objetivos, se contempla la protección del medio natural y de los elementos paisajísticos más importantes del municipio, así como la reducción de los impactos urbanísticos (Navalón, 1995:100). Sin embargo, sigue considerando la posibilidad de construir edificaciones unifamiliares ligadas al aprovechamiento agrícola (Navalón, 1995:102; Such, 1995:172), que aún mantiene un cierto desarrollo en la parte más accesible de las laderas y barrancos (Antolín, 1990:101). Además, la administración se enfrenta al problema de tener que legalizar las construcciones anteriores, las parcelaciones ilegales y todas las manchas de suelo urbano surgido por consolidación espontánea y carente de infraestructura (Vera, 1987:316).

5 Construcción rural tradicional utilizada fundamentalmente en la Marina Alta para la producción de pasa. 
En consecuencia, buena parte de los terrenos de pinar y de sotobosque son destinados al uso residencial a partir del planeamiento parcial (Puchol, La Corona, Rafalet, Cap Martí, Mar Azul), con el que se ocupan masivamente los espacios de mayor valor natural con la correspondiente degradación y transformación paisajística. Únicamente quedan libres algunos sectores de utilidad pública en el propio parque (Such, 1995:172), si bien sus laderas ya se encontraban fuertemente salpicadas por la edificación dispersa. En definitiva, el fomento del turismo y la creación de enormes urbanizaciones han terminado con un buen número de masas forestales y han generado la proliferación de unidades fragmentadas debido a las parcelaciones. Graves efectos que se suman a los ocasionados por los continuos incendios, especialmente intensos durante los años noventa.

Ya en la segunda mitad de esa misma década, Jávea entra en un periodo marcado por el extraordinario impulso económico del país, que perdura hasta los años 2007-2008. La llegada de turistas y residentes nacionales y europeos, así como de trabajadores ocupados mayoritariamente en la construcción y los servicios provoca un notable aumento de la población entre 1996 y 2008 (145,6\%, conforme datos del INE). En estrecha relación, y de acuerdo al IVE, se produce un incremento del área construida de unas 130 ha, cerca del $2 \%$ de la superficie municipal, debido al empuje del turismo residencial que, a pesar de la evidente saturación urbanística, sigue ocupando amplios sectores de suelo. En las laderas del Montgó, dentro de los límites del PORN y junto a los del parque natural, se llevan a cabo actuaciones para ampliar urbanizaciones ya existentes (La Corona, Xàbia Blanca, L'ermita, Montgó-Toscamar, Castellans-Rimontgó), a menudo tras cambios de uso de suelo de agrícola a residencial e incluso sin previa autorización. Actuaciones que no solo ocupan indebidamente terreno calificado como SNU sino también conectores ecológicos y áreas del interior del espacio protegido. Cabe señalar que en este sector municipal no estaba permitida la edificación, puesto que el PGOU de 1990 estuvo paralizado durante unos años, y de ahí que muchas de estas nuevas construcciones carecieran de las pertinentes licencias de obras o informes favorables.

En efecto, el crecimiento urbanístico de Jávea alcanzó tal nivel de descontrol que en 2007 las propias autoridades locales solicitan al Consell la suspensión temporal de parte de su PGOU de 1990, que, por otro lado, había incorporado más de sesenta modificaciones puntuales. De esta manera, se paralizan las licencias de parcelación de terrenos, de edificación y demolición para determinadas áreas del término municipal hasta la entrada en vigor de un nuevo planeamiento urbano, para el que establece un plazo máximo de cuatro años. Con ello, y según expone el propio planeamiento, se «pretende alcanzar el equilibrio territorial en una de las zonas de mayor afluencia turística (...) evitando que la dinámica de la actividad inmobiliaria dificulte o llegue a impedir la consecución del modelo territorial que se pretende implantar». Desde entonces, se ha elaborado un documento consultivo (2010) y se ha elaborado un Texto Refundido del PGOU (versión de 2013), sometido primero a información pública y posteriormente aprobado por el pleno del Ayuntamiento en mayo de 2013.

En este sentido, cabe llamar la atención acerca de que la suspensión temporal aplicada en el año 2007 llegó a caducar, dejando en el limbo normativo terrenos de gran valor ecológico en las faldas del Montgó. Es el caso del sector denominado Huertos del Montgó para el que en se planteó un PAI con el que se pretendía construir un complejo asistencial-sanitario compuesto de viviendas adosadas e infraestructuras de diverso tipo (supermercado, pistas 
Figura 3

EVOLUCIÓN URBANO-TURÍSTICA DE JÁVEA CON ESPECIAL INCIDENCIA EN EL MONTGÓ

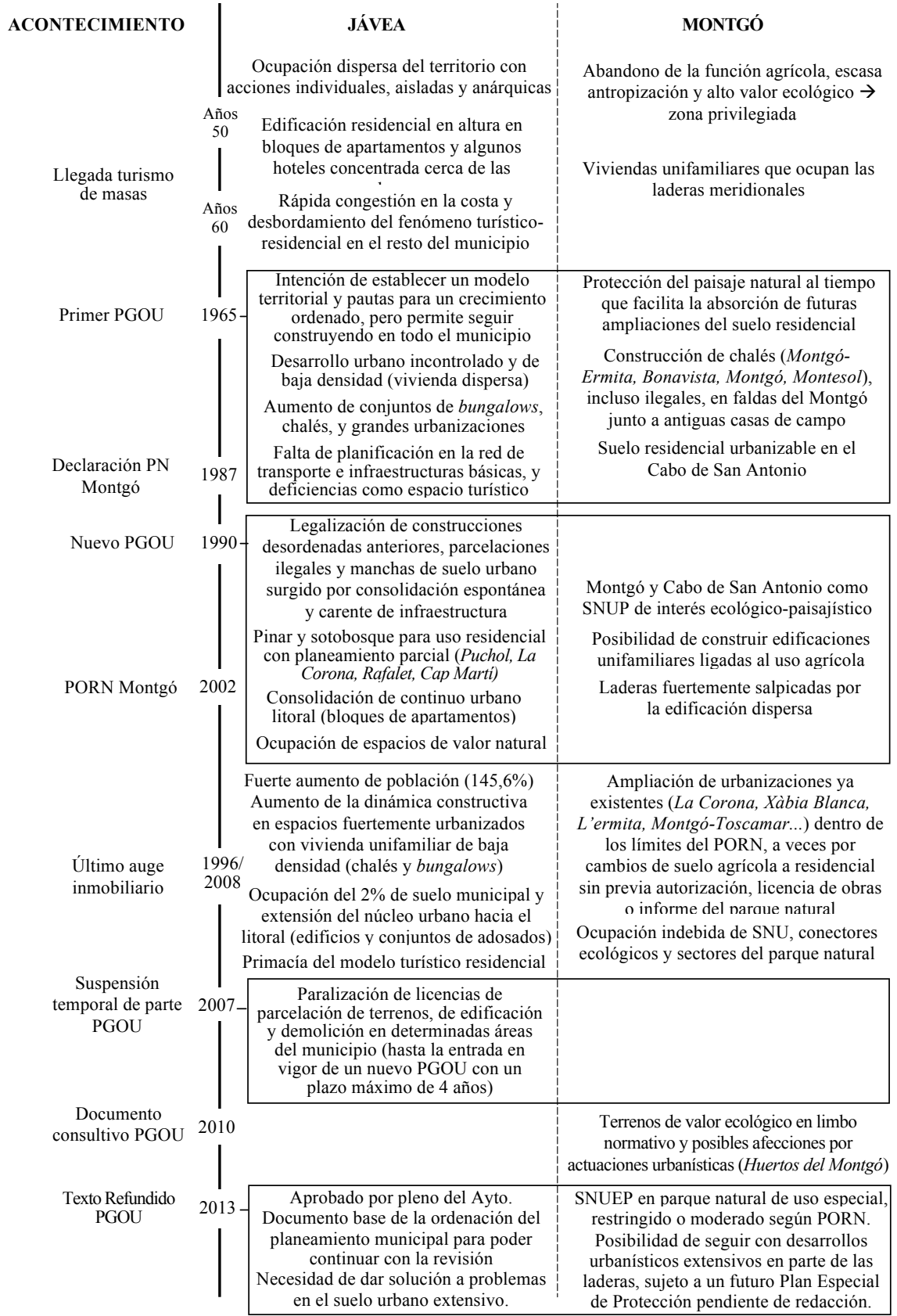

Fuente: elaboración propia. 
de tenis y pádel, piscinas, club social, consultas de médico y fisioterapeuta, entre otras $)^{6}$. El conflicto urbanístico viene dado porque una parte de dicha finca se encuentra en un corredor ecológico y limita con áreas LIC y ZEPA del Montgó y el Cabo de San Antonio, además de que la edificación podría aumentar el riesgo de contaminación del subsuelo y los acuíferos ${ }^{7}$.

En cuanto al Parque Natural del Montgó, el Texto Refundido de 2013 mantiene su condición de SNUEP, con diversidad de usos (especial -campo de tiro-, moderado o restringido) en función del PORN, aunque no así parte de las laderas que lo circundan, en las que se permite la posibilidad de seguir con desarrollos urbanísticos extensivos a partir del planeamiento parcial que debe estar sujeto a un futuro plan especial de protección, también pendiente de redacción.

Por último señalar que, según el concejal de urbanismo ${ }^{8}$, se trata de un documento base de la ordenación del planeamiento de todo el término municipal para poder continuar con la revisión. Además, se está preparando una propuesta de ordenación pormenorizada que afecta a alineaciones, usos y normativa urbanística que dé solución a problemas existentes en el suelo urbano extensivo, que es el de mayor superficie y sobre el que más se actúa, para resolverlo lo antes posible.

\section{V.2. El Parque Natural de las Lagunas de la Mata y Torrevieja: un espacio de tradicional explo- tación salinera}

Como se observa en la Figura 4, el Parque Natural de las Lagunas de la Mata y Torrevieja (3743 ha) es una gran zona húmeda de origen tectónico compuesta por dos láminas de agua: la laguna de Torrevieja, de mayores dimensiones, y la laguna de la Mata, más pequeña y próxima a la costa. Es un espacio de flora predominantemente halófila donde existen varios ambientes; en las lagunas hay una cierta ausencia de vegetación, y en los sectores circundantes existen comunidades de saladar, y formaciones de carrizal y juncal. En cuanto a la fauna, el invertebrado más característico es la Artemia salina, clave para la presencia de especies de avifauna acuática como la avoceta, el aguilucho cenizo, el tarro blanco, la gaviota de Adouin o el flamenco rosa, todas ellas representativas de este entorno declarado parque natural en el año 1996.

Ocupadas ya desde época íbera, para revisar la historia de las lagunas hay que tener en cuenta la cuestión de la propiedad. En el s. XIV ambas son cedidas a Orihuela, que tiene la posibilidad de transformar la laguna de Torrevieja y aprovecharla como recurso pesquero. Sin embargo, el fracaso de la actividad y el elevado coste del mantenimiento provocarían la renuncia por parte de la ciudad por lo que mediados del s. XVIII pasan a ser propiedad estatal. Tras unas primeras pruebas en la laguna de la Mata, se comienza a obtener sal de forma organizada hasta que un siglo después el Estado impone la idea de arrendar las salinas, momento a partir del cual la explotación ha ido mejorando significativamente hasta la actualidad. Si bien el turismo y otros sectores vinculados se han convertido en las últimas décadas en el verdadero motor socioeconómico de Torrevieja, la industrial salinera sigue manteniendo un muy peso muy importante.

6 «Una inmobiliaria construirá 300 casas para jubilados europeos en Dénia y Xàbia» Diario Información, $30 / 5 / 2014$.

7 Terol, E. «Xàbia facilita un complejo residencial en el Montgó». Diario El País, 31/8/2012.

8 «Pere Sapena explica la situación del Plan General de Ordenación Urbana» www.javea.com 13/2/2015. 


\section{V.2.1. Torrevieja, el paradigma del turismo residencial}

En los años sesenta del siglo pasado, en un contexto marcado por el desarrollismo económico en todo el país, el turismo de masas irrumpe con fuerza en Torrevieja y se consolida a partir de la década siguiente. Una de las claves del nuevo modelo de desarrollo es la extraordinaria revalorización del suelo que originó procesos especulativos a través de los cuales los compradores se interesan por una tierra de función agrícola cada vez menos productiva para convertirla en suelo de vocación turístico-residencial. Como resultado, se da inicio a la construcción de grandes bloques de apartamentos en el litoral (Vera, 1987:189), que acaban por alterar la franja costera por completo. Ese fue el germen de la enorme transformación socioeconómica y urbana que ha experimentado Torrevieja durante las últimas décadas, y que ha llevado al municipio a representar el paradigma del proceso urbanizador y un centro turístico de primer orden (Torres, 1995:78).

Si bien el primer PGOU no se aprueba hasta 1973, Torrevieja ya contaba con proyectos apoyados en el planeamiento parcial que generaron una «auténtica avalancha de actuaciones urbanizadoras» (Navalón, 1995:171). Son actuaciones destinadas a la construcción de chalés en el espacio rural (Rocío del Mar, Villa Sol, Molino Blanco, Lomas del Mar, la Veleta), y favorecidas por la estructura agraria tradicional, donde predomina la mediana y grande propiedad, así como la existencia de espacios libres en el contorno de las lagunas (Vera, 1987:360). Con el nuevo plan, el núcleo urbano crece en varias direcciones, y se crea un modelo desmesurado, masificado y escasamente integrado en el paisaje, en especial en la ribera este de la laguna meridional (La Torreta, El Chaparral, San Luis, La Siesta, Punta de la Víbora), convertida en una de las principales zonas de expansión (Such, 1995:237). Para Vera (1984:127), «la especulación penetra hacia las tierras del interior; las urbanizaciones se extienden y enseñorean del espacio que bordea la laguna de las salinas, a expensas de las tierras de cultivo o de los saladares (...) que se convierten en superficies edificables, con un evidente deterioro paisajístico y fuertes tensiones espaciales».

Por ello, en 1986 se aprueba un nuevo PGOU cuya memoria ya advertía del fracaso del plan anterior (Torres, 1997:39), y que muestra especial interés por frenar la expansión desordenada a partir de un desarrollo urbanístico menos especulativo y más respetuoso con los espacios de valor natural. Sin embargo, muchas de las actuaciones previstas en el plan anterior ya habían sido aprobadas y fue imposible paralizarlas. De manera que en los años posteriores al nuevo planeamiento se produce un desarrollo mucho más congestionado y caótico, resultando un modelo de ciudad que nada tenía que ver con las pretensiones iniciales del mismo. Se consolida la edificación paralela al mar y se da vía libre a la ocupación turístico-residencial en el entorno de las lagunas, invadido por nuevos conjuntos de bungalows o adosados de baja calidad (La Torreta III, Limonar III, Limonar V) que se van anexionando a los allí edificados. Para Torres (1997:153), estas actuaciones fueron de «suma transcendencia por haber determinado, con su presencia, unos límites artificiales para el [futuro] parque natural». El mejor ejemplo de esta propagación edificatoria se produce durante la segunda mitad de los ochenta cuando, en plena «borrachera inmobiliaria» (Torres, 1995:83), se colmata el Chaparral, una pequeña elevación que separa las dos lagunas, donde ya proliferaban las edificaciones (VV.AA., 1990:113). De hecho, este fue uno de los principales detonantes para que en el año 1988 ambas lagunas fueran protegidas, en un primer momento, bajo la 


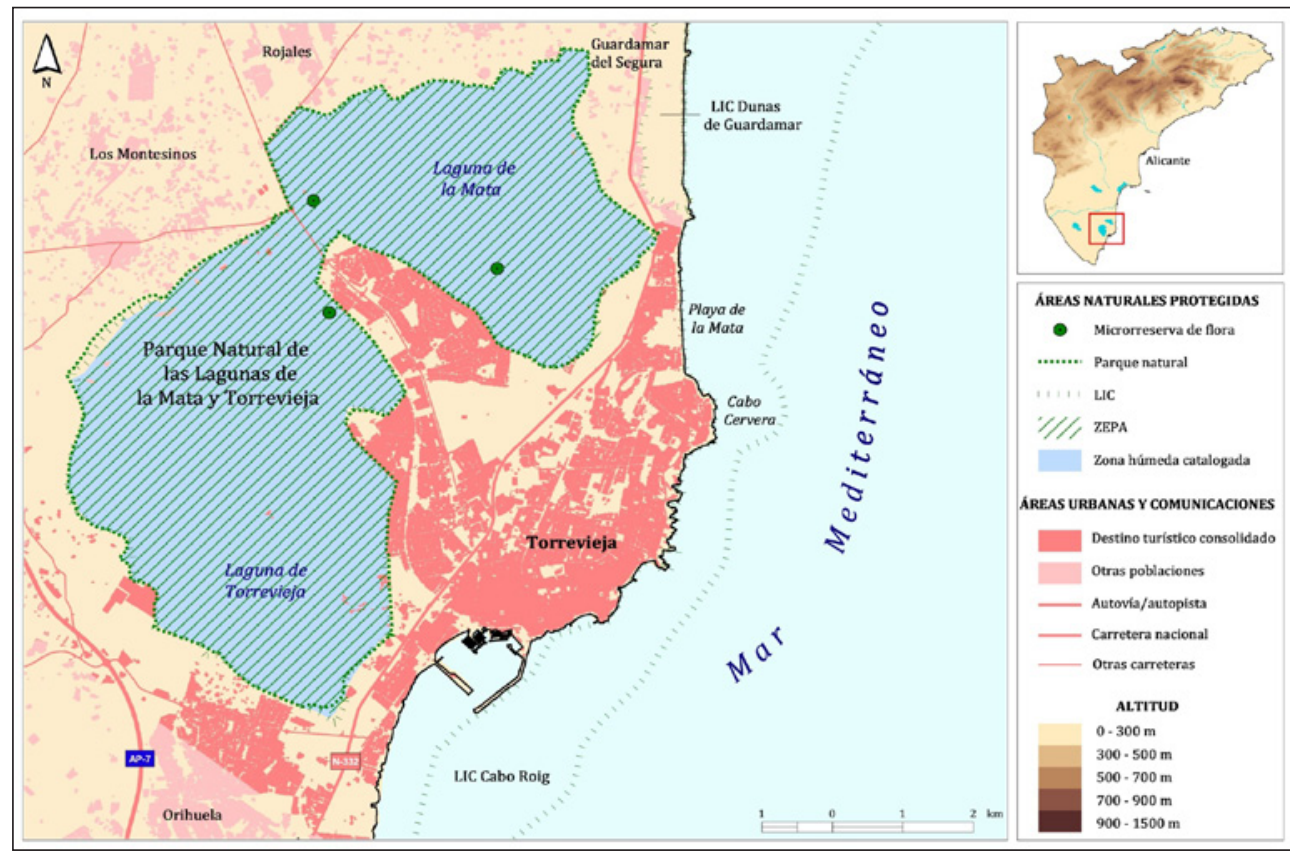

Fuente: elaboración propia a partir de la base cartográfica del Terrasit.

figura de paraje natural, y, posteriormente, reclasificadas como parque natural con la ley de 1994. Se evidencia así el acelerado proceso de desarrollo urbano-turístico y la consecuente excesiva presión que seguía sufriendo este humedal costero.

Desde entonces, y lejos de lo que cabría esperar, la dinámica turístico-residencial no ha dejado de de ejercer una creciente amenaza sobre las lagunas, en especial tras el enorme crecimiento demográfico y urbano experimentado desde mediados de los años noventa. En apenas diez años (1996-2008), y de acuerdo a las estadísticas ofrecidas por el INE, la población de Torrevieja experimentó un incremento del 281,6\%. Asimismo, y pese a que la reserva del suelo disponible estaba prácticamente agotada, se abrió un nuevo periodo de extraordinario auge inmobiliario a partir de continuas modificaciones puntuales introducidas tanto en el PGOU de 1986 como en el Texto Refundido del año 2000 (más de un centenar hasta la actualidad), muchas de ellas con el fin de liberar suelo. De acuerdo con los datos del IVE, durante esos mismos años se concedieron un total de 53.634 licencias de obra para la edificación de viviendas de nueva planta con las que se urbanizaron un total de 550 ha, el 7,6\% de la superficie municipal. Así, se levantan y amplían conjuntos de adosados repartidos por todo el término municipal (El Peinado, Aguas Nuevas, Paraje Natural, La Lloma, Torreblanca), se ocupan solares y parcelas libres en el caso urbano con bloques de viviendas, y se crean grandes espacios destinados a usos industriales, comerciales, deportivos y recreativos. Y todo ello sin contar las edificaciones construidas de manera ilegal. 
Figura 5

EVOLUCIÓN URBANO-TURISTICA DE TORREVIEJA, CON ESPECIAL INCIDENCIA EN LAS LAGUNAS

\section{ACONTECIMIENTO

Llegada turismo
de masas

Primer PGOU

\section{Nuevo PGOU}

Declaración Paraje Natural Lagunas la Mata-Torrevieja

\section{Declaración PN Lagunas la Mata- Torrevieja}

Texto refundido
PGOU

Último auge inmobiliario

PORN SZHSA $\stackrel{1}{2010-1}$

\section{TORREVIEJA}

s. XIX Núcleo de veraneo tradicional I Barracas y casetas para el baño en la $1^{\text {a }}$ mitad costa, y algunas residencias s. XX veraniegas («hotelitos») y pequeños grupos de chalés

Construcción de bloques de apartamentos en el litoral que reemplazan los establecimientos tradicionales Revalorización de la tierra de escaso Años valor agrícola para convertirla en suelo 60 de vocación turístico-residencial. Planeamiento parcial para levantar conjuntos de chalés en espacio rural (Rocio del Mar, Villa Sol, Molino Blanco, Lomas del Mar) casi desocupado y con grandes propiedades.

1973- Desarrollo en varias direcciones con un modelo desmesurado, masificado, de bajas calidades constructivas, y escasamente integrado en el paisaje Ocupación litoral con alto precio de suelo

\section{Objetivo: frenar la expansión} desordenada con un desarrollo menos especulativo y más respetuoso con los espacios naturales

Imposibilidad de paralizar actuaciones aprobadas y previstas en el plan del 73

Modelo urbano de baja densidad

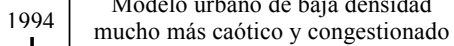

Consolidación de la edificación paralela al mar

\section{Aumento de población del $281,6 \%$}

Pese al agotamiento, se reclasifica y libera suelo a partir de numerosas modificaciones puntuales (un centenar)

Construcción de miles de nuevas viviendas, algunas ilegales, con las que se ocupa el $7,6 \%$ de suelo municipal 1996/ Edificación y ampliación de conjuntos 2008 de adosados (El Peinado, Aguas Nuevas,

Paraje Natural, La Lloma ...) en el término municipal

Ocupación de solares y parcelas libres en el caso urbano con bloques de viviendas.

Creación de grandes espacios destinados a usos industriales, comerciales, recreativos y deportivos.

Torrevieja como auténtico paradigma del turismo residencial

\section{LAGUNAS DE LA MATA Y TORREVIEJA}

Explotación salinera en la laguna de Torrevieja, primero bajo tutela estatal y, posteriormente, por arrendamiento.

Gran peso de la actividad en la economía local

Primeras intervenciones de tipo urbanístico en el contorno de las lagunas
Crecimiento hacia el borde oriental de la laguna de Torrevieja (La Torreta, El Chaparral, San Luis, La Siesta, Punta de la Víbora) apoyado en la C-3321 (hoy CV-905).

Clasificación de las lagunas como SNU

Vía libre a la ocupación turísticoresidencial en el margen oriental de la laguna de Torrevieja, una de las principales zonas de expansión, donde se levantan conjuntos de bungalows y adosados (La Torreta III, Limonar III,

Limonar V) junto a los construidos Escasa ocupación del borde suroccidental, clasificado como SNU Ocupación de la ladera sur del Chaparral

Fuerte aumento de la presión urbanística en las inmediaciones del parque natural. Incremento de la función residencial, especialmente de media y baja densidad.

Construcción de importantes infraestructuras (Hospital, desalinizadora), y ampliación de la depuradora, en su área de influencia.
Recalificación de unas 200 ha de suelo protegido en urbanizable en El Limonar, uno de los pocos espacios desocupados junto a la laguna de Torrevieja, y $E l$ Raso al norte de la laguna de la Mata

Elaboración propia. 
De otro lado, el Ayuntamiento recalificó cientos de hectáreas de terrenos rústicos donde autorizaba proyectos urbanísticos que se sumaban a la construcción de grandes infraestructuras en el área de influencia del parque natural, junto a los límites del PORN del Sistema de Zonas Húmedas del Sur de Alicante (en adelante, SZHSA) aprobado en $2010^{9}$. En otras ocasiones ha sido este mismo documento el que ha seguido «arañando» suelo del perímetro de protección (Greenpeace, 2009:142) con la recalificación de unas 200 ha de suelo protegido en urbanizable. Terrenos que han sido destinados a la futura construcción de macrourbanizaciones como $E l$ Limonar, en uno de los pocos espacios desocupados que quedan junto a la laguna de Torrevieja, y la ampliación de otras como la del El Raso, al norte de la laguna de la Mata en el vecino municipio de Guardamar del Segura, que ya está urbanizada y parcialmente edificada.

Torrevieja se ha convertido así en uno de los espacios de mayor concentración de vivienda residencial no solo de la Costa Blanca, sino de todo el litoral mediterráneo español. El destino ha mantenido el modelo de ocupación heredado, definido por un crecimiento de carácter extensivo a partir de un elevado número de actuaciones de media y baja densidad que han ido invadiendo grandes superficies de suelo, incluidas las inmediaciones del parque natural. En este sentido, tal y como señalan Martí y Nolasco (2011:376), es muy significativo que sea de manera simultánea cuando se crea el parque y se urbanizan los espacios intersticiales y aledaños al mismo. Incluso se ha llegado a utilizar el propio espacio protegido como reclamo para la venta inmobiliaria (Torres, 1997:135), a pesar de que las lagunas están clasificadas como SNU en el PGOU en tanto en cuanto «independientemente de su interés económico como explotación salinera, destacan por su interés como zona húmeda».

\section{CONCLUSIONES}

Con la llegada del turismo de masas a las costas valencianas en los años sesenta se da inicio a un desarrollo turístico-residencial cuya primera etapa se caracteriza por la ausencia de un adecuado planeamiento urbano que favoreció un crecimiento espontáneo, especulativo y según necesidades privadas por encima de intereses generales, mediante actuaciones parciales e intervenciones, a menudo, ilegales, y con el beneplácito de un marco institucional y administrativo muy débil. Cuando los efectos de este desarrollo son ya evidentes, se acometen los primeros intentos de estructurar el territorio a partir de una primera generación de PGOU contradictorios, permisivos e ineficientes, que se veían obligados a legalizar las construcciones ya levantadas, y materializar aquellos proyectos aprobados con anterioridad. En consecuencia, se produce un crecimiento aún más desmedido, caótico e incontrolado que autoriza actuaciones dispersas y de baja densidad en terrenos de gran valor ecológico y paisajístico, declarados suelos urbanizables. Dinámica que no cambia en exceso ni con la revisión del planeamiento y la posterior aprobación de nuevos PGOU, ni con las medidas conservacionistas llevadas a cabo por el gobierno regional en los años ochenta y noventa. Máxime si se tiene en cuenta que muchos de los ENP creados por entonces no fueron acompañados de los instrumentos de planificación y gestión correspondientes, redactados generalmente con un considerable retraso.

9 El SZHSA es un conjunto de humedales formado por Las Lagunas de la Mata y Torrevieja, las Salinas de Santa Pola y el Hondo que comparten un mismo PORN como principal documento normativo. 
Con todo, si hace unas décadas el acoso sobre el territorio era tan intenso como para forzar actuaciones urgentes de protección, la realidad no ha evolucionado en positivo sino que se ha agravado notablemente. Pese a las escasas posibilidades de mantener el mismo ritmo de crecimiento, el último auge económico se ha materializado en esta región con un marcado aumento demográfico y urbanístico, en algunos municipios los mayores de toda su historia. Al mismo tiempo, se mantiene vigente una segunda generación de PGOU que, en lugar de cumplir sus funciones, siguen presentando una enorme permisividad, además de quedar obsoletos con prontitud ya que difícilmente podían prever los fuertes impulsos acontecidos pocos años después de ser aprobados. De ahí los continuos planes parciales, las numerosas modificaciones puntuales en la clasificación y calificación para liberar suelo según las necesidades inmobiliarias, y las aprobaciones de textos refundidos, así como las distintas anulaciones y suspensiones que, en contrapartida, han sufrido varios planes. En otras palabras, entre los años 1996 y 2008 no solo se ha producido una nueva etapa de desorbitado crecimiento urbanístico, mucho más intensa que décadas pasadas, sino que se ha llevado a cabo en un marco de actuación incluso más inoperante que el de los primeros años de desarrollismo.

En definitiva, se ha intensificado aún más la magnitud de la presión ejercida sobre el territorio, en general, y los ENP del litoral, en particular, y se ha continuado con la destrucción de sus valores más importantes. Los enfrentamientos entre los distintos intereses que se solapan en el territorio han generado muchos de los conflictos que hoy en día existen en terrenos próximos a los parques naturales. Varios de ellos están motivados por los intentos de ejecutar operaciones turístico-inmobiliarias que, precisamente, tratan de aprovechar los vacíos normativos y vaguedades del planeamiento, y todo ello en un marco de supuesta armonía medioambiental.

En este sentido, es preciso insistir en la debilidad de los instrumentos de planificación y gestión de los ENP los cuales, según la legislación vigente, deben prevalecer sobre los el planeamiento urbanístico. Sin embargo, como se ha tenido oportunidad de ver en los ejemplos presentados, la realidad demuestra que son dichos instrumentos los que, por lo general, quedan supeditados a los planes de ordenación urbana. Este es el fiel reflejo de lo que ha pasado a llamarse «parques de papel» (paper parks), término con el que Greenpeace (2010:65) designa aquellos ENP cuya declaración únicamente se efectúa sobre un mapa, pues carecen de medidas de gestión reales. Se trata de una realidad que define perfectamente la situación actual del litoral valenciano donde los espacios naturales costeros se encuentran «asfixiados por el ladrillo y hormigón». De ahí también ese «proceso contradictorio» del que hablan Martí y Nolasco (2011:378) a través del cual se han ido poniendo en valor varios parques naturales junto al litoral valenciano, al tiempo que se ha producido una fuerte artificialización de los entornos cercanos y limítrofes a esos mismos espacios. En este sentido, resultan muy acertadas las palabras de Santamarina (2008:39) según las cuales parece que el «afán de protección y de multiplicación de espacios protegidos sea una compensación simbólica, más que real, al brutal proceso urbanizador experimentado».

Por otro lado, no hay que perder de vista otras cuestiones que, sin ánimo desviar en exceso las reflexiones finales de este trabajo, son realidades que, sin duda alguna, subyacen en muchos temas que han sido objeto de estudio del mismo. Bien es cierto que la construcción y promoción de vivienda para el turismo ha tenido un peso muy importante en el modelo de desarrollo económico de esta región durante décadas, y más intensamente en los 
años que duró el último auge inmobiliario, sin embargo, una vez sobreviene la crisis y cesa la intensa actividad inmobiliaria, la Comunidad Valenciana comienza a experimentar unos graves efectos. La dependencia de dicha actividad deriva en que esta sea una de las autonomías españolas con mayor deuda pública y que muchos de sus municipios más importantes se encuentren entre los más endeudados del país, pues son incapaces de hacer frente al enorme gasto que supone el mantenimiento de los servicios. De igual forma, la región está sufriendo significativamente los impactos en el empleo relacionado con la construcción y las actividades afines, ya que buena parte de los puestos de trabajo se generaron por un hecho coyuntural como fue el boom inmobiliario.

Y en este contexto, no debe sorprender que en estos últimos años la región sea a menudo noticia por repetidos casos de corrupción vinculados al urbanismo y a distintos servicios públicos en los que se ven envueltos, entre otros, responsables políticos y empresarios afines. Tampoco el resultado final de muchos grandes proyectos urbanísticos, de infraestructuras de transporte e importantes eventos que hoy en día presentan un estado muy diferente al que se esperaba de ellos cuando fueron emprendidos. Del mismo modo, no resultan extrañas la desaparición, fusión y/o absorción de algunas de las principales entidades bancarias valencianas, ni los problemas de financiación de muchos y distintos organismos públicos como consecuencia de las medidas de ahorro, maximización y optimización de recursos económicos y humanos llevadas a cabo por diferentes administraciones públicas.

\section{BIBLIOGRAFÍA}

ALMENAR ASENSIO, R., BONO MARTÍNEZ, E. y GARCÍA GARCÍA, E. (2000): La sostenibilidad del desarrollo: el caso valenciano. Valencia. Fundación Bancaixa y Universitat de València.

ANTOLÍN TOMÁS, M.C. (1990): Parque Natural del Montgó. Estudio multidisciplinar. Valencia. Agència del Medi Ambient. Conselleria d'Administració Pública.

ANTON CLAVÉ, S. (2004): «De los procesos de diversificación y cualificación a los productos turísticos emergentes. Cambios y oportunidades en la dinámica reciente del turismo litoral», en Papeles de Economía Española, 102, 316-333.

ARTIGUES, A. y RULLÁN, O. (2007): «Nuevo modelo de producción residencial y territorio urbano disperso (Mallorca, 1998-2006)», en GeoCrítica, XI, 245 (10). Disponible en http://www.ub.edu/geocrit/sn/sn-24510.htm

BAÑOS CASTIÑEIRA, C.J. (1999): «Modelos turísticos locales. Análisis comparado de dos destinos de la Costa Blanca». Investigaciones Geográficas, $\mathrm{n}^{\circ}$ 21, 35-58.

BLÁZQUEZ SALOM, M. (2007): «Los espacios naturales, "el mango de la sartén va al otro lado"», en GeoCrítica, 245 (37). Número extraordinario dedicado al IX Coloquio de GeoCrítica. Disponible en http://www.ub.edu/geocrit/sn/sn-24537.htm.

BURRIEL DE ORUETA, E. (2008): «La “década prodigiosa" del urbanismo español (19972006)», en Scripta Nova, 270. Disponible en http://www.ub.edu/geocrit/sn/sn-270/ sn-270-64.htm.

CERVERA ARBONA, I., RAFET SORIANO, J.M., RIPOLL BERENGUER, M.J. i SÁNCHEZ CABRERA, J.V. (2013): «Mobilitzacions i conflictes derivats de la protección ambiental a la Marina Alta», en Aguaits. Revista d'investigació i assaig, n 32-33, 75-96. 
COSTA MÁS, J. (1977): El Marquesat de Dénia. Estudio geográfico. Valencia. Universidad de Valencia, Departamento de Geografía de Valencia.

CRUZ, J., DONAT, M. y RODRÍGUEZ, J. (2002): «Metodología para el estudio de frecuentación de un espacio protegido. El caso del "Parque Natural del Montgó" (Alicante, España)», en Turismo en espacios naturales y rurales II (Viñals Blasco, M.J., Ed.) Valencia, UPV, 237-252. CRUZ OROZCO, J. y SUCH CLIMENT, M.P. (2001): «Los espacios protegidos», en La periferia emergente. La Comunidad Valenciana en la Europa de las regiones (Romero J., Morales, A., Salom J. y Vera, F., coord.). Barcelona, Ariel Geografía, 551-579.

DELGADO VIÑAS, C. (2008): ««Urbanización sin fronteras», el acoso urbanístico a los espacios naturales protegidos», en Boletín de la AGE, 47, 271-310. Disponible en http:// age.ieg.csic.es/boletin/47/13-DELGADO.pdf.

DELGADO VIÑAS, C. (2012): «Secuelas territoriales de la "burbuja inmobiliaria" en las áreas protegidas litorales españolas», en Ciudad y Territorio, 174, pp. 615-637.

DÍAZ ORUETA, F. (2004): «Turismo, urbanización y cambio social», en Revista Argentina de Sociología, 2, 115-127.

DÍAZ ORUETA, F. y LOURÉS SEOANE, M.L. (2008): «La globalización de los mercados inmobiliarios: su impacto en la Costa Blanca», en Ciudad y Territorio, 155, 77-92.

ECOLOGISTAS EN ACCIÓN (2007): Banderas negras 2007, metástasis costeras, 142 pp. Disponible en http://www.ecologistasenaccion.org/IMG/pdf_Informe_Banderas_ Negras_2007.pdf

EUROPEAN ENVIRONMENT AGENCY (EEA) (2006): Urban sprawl in Europe. The ignored challenge. Disponible en http://www.eea.europa.eu/publications/eea report_2006_10/eea_report_10_2006.pdf/view.

FERNÁNDEZ DURÁN, R. (2006): El tsunami urbanizador español y mundial. Barcelona, Virus Editorial.

FERNÁNDEZ GARCÍA, A. (2003): «Las pautas de crecimiento urbano postindustrial: de la rururbanización a la ciudad difusa», en Ería, 60, 88-92. Disponible en http://www.revistaeria.es/index.php/eria/article/view/576/554.

FERNÁNDEZ MUÑOZ, S. (2003): «El PORN del Montgó: entre la planificación ambiental y la ordenación del territorio». Boletín EUROPARC-España, $\mathrm{n}^{\circ}$ 15, 41-43.

GAJA I DÍAZ, F. (2005): «El suelo como excusa: el desarrollismo rampante», en Boletín $C F+S, 29-30$. Disponible en http://habitat.aq.upm.es/boletin/n29/afgaj.html.

GAJA I DÍAZ, F (2008a): «Urbanismo ecológico, ¿sueño o pesadilla?», en Revista Internacional de Sostenibilidad, Tecnología y Humanismo, 3, 105-126. Disponible en http:// upcommons.upc.edu/revistes/bitstream/2099/7079/1/gaja.pdf.

GAJA I DÍAZ, F. (2008b): «El "tsunami urbanizador” en el litoral mediterráneo. El ciclo de hiperproducción inmobiliaria 1996-2006», en Scripta Nova, 270. Disponible en http:// www.ub.edu/geocrit/sn/sn-270/sn-270-66.htm\#_edn1

GREENPEACE (2005, 2010): Destrucción a toda costa. Informe sobre la situación del litoral español. Greenpeace España. Disponible en http:/www.greenpeace.org/espana/es/

GREENPEACE (2009): Destrucción a toda costa. Situación del litoral español y sus espacios protegidos. Greenpeace España. Disponible en http://www.greenpeace.org/espana/ Global/espana/report/costas/informe-completo-destrucci-n.pdf. 
HERNÁNDEZ LEÓN, E. (2008): «De parques naturales a parques urbanos. Turismo y patrimonialización del territorio en áreas protegidas», en BELTRÁN, O., PASCUAL, J.J. y VACCARO, I. (Coord.): Patrimonialización de la naturaleza. El marco social de las políticas ambientales, Actas XI Congreso de Antropología de la FAAEE. ANKULEGI antropologia elkartea, pp. 83-96. Disponible en http://www.ankulegi.org/9-patrimonializacion-de-la-naturaleza-el-marco-social-de-las-politicas-ambientales/

HUETE NIEVES, R., MANTECÓN TERÁN, A. y MAZÓN MARTÍNEZ, T. (2008): «¿De qué hablamos cuando hablamos de turismo residencial?», en Cuadernos de turismo, 22, 101-121. Disponible en http://revistas.um.es/turismo/article/view/48091/46071

LÓPEZ DE LUCIO, R. (1993): Ciudad y urbanismo a finales del siglo XX. València, Universitat de València, Servei de Publications.

MARTÍ, P. y NOLASCO, A. (2011): «La expansión urbanística reciente de la costa alicantina, una realidad constatable», en Geografía y desafíos territoriales en el siglo XXI: Urbanismo expansivo: de la utopía a la realidad (Gonzálvez, V. y Marco, J.A., coord.). Alicante. Universidad de Alicante, 367-378.

MATA OLMO, R. (2007): Auge inmobiliario y evolución de los usos del suelo en España. Por una nueva cultura del territorio. Lección inaugural para la apertura del curso académico 2007/2008. Escuela Politécnica Superior Universidad Autónoma de Madrid. Disponible en http://www.universidadambientaldelapalma.es/seminario2008/descargas/docs/RMO.1.pdf

MAZÓN MARTÍNEZ, T. y ALEDO TUR, A. (2005): «El dilema del turismo residencial: ¿turismo o desarrollo inmobiliario?», en MAZÓN, T. y ALEDO, A. (Eds.): Turismo residencial y cambio social: nuevas perspectivas teóricas y empíricas. Alicante: CAM, Fudación Fax y Universidad de Alicante, pp. 13-30.

MINISTERIO DE MEDIO AMBIENTE (MMA) (2008): Expansión urbana descontrolada en Europa. Un desafío olvidado.

NAVALÓN GARCÍA, R. (1995): Planeamiento urbano y turismo residencial en los municipios litorales de Alicante. Alicante. Instituto de Estudios Juan Gil-Albert.

OBIOL MENERO, E.M. y PITARCH GARRIDO, M.D. (2011): «El litoral turístico valenciano. Intereses y controversias en un territorio tensionado por el residencialismo», en Boletín de la AGE, 56, 177-200.

OBSERVATORIO DE LA SOSTENIBILIDAD EN ESPAÑA (OSE) (2006): Cambios de ocupación del suelo en España. Implicaciones para la sostenibilidad. Disponible en http:// www.sostenibilidad-es.org/sites/default/files/_Informes/tematicos/suelo/suelo-esp.pdf.

ORGANIZACIÓN DE LAS NACIONES UNIDAS (ONU) (2014): World urbanization prospects. The 2014 revision. Disponible en http://esa.un.org/unpd/wup/Highlights/ WUP2014-Highlights.pdf

ORS, J. y VIÑALS BLASCO, M.J. (1995): «Las políticas de protección y gestión de los recursos naturales de la Generalitat Valenciana», en Cuadernos de Geografía, 58, 289306. Disponible en http://www.uv.es/cuadernosgeo/CG58_289_306.pdf.

PELLICER CORELLANO, F. (2001): «El impacto ambiental de los procesos de concentración económica», en Los espacios litorales y emergentes. Lectura geográfica. Actas del XV Congreso de Geógrafos Españoles. Santiago de Compostela, Servicio de Publicaciones de la Universidad de Santiago de Compostela, 351-376. 
PERELLI DEL AMO, O. (2011): «Por una nueva cultura del litoral basada en su revalorización turística como motor de la recuperación», en Papeles de economía española, 128, 53-71.

PONCE HERRERO, G. (2006): «La fragmentación de la forma urbana en la Comunidad Valenciana», en G. PONCE (Ed.): La ciudad fragmentada. Nuevas formas de hábitat. Alicante: Publicaciones de la Universidad de Alicante, pp. 89-129.

PRADOS VELASCO, M. J. (2006): «Los parques naturales como factor de atracción de la población. Un estudio exploratorio sobre el fenómeno de la naturaleza en Andalucía», en Cuadernos Geográficos, 38, 87-110. Disponible en http://www.ugr.es/ cuadgeo/docs/ articulos/038/038-005.pdf.

PRIETO, F.; CAMPILLO LLANOS, M. y DÍAZ PULIDO, J.M. (2011): «Tendencias recientes de evolución del territorio en España (1987-2005): causas y efectos sobre la sostenibilidad», en Ciudad y Territorio, 168, 261-278.

PULIDO FERNÁNDEZ, J.I. (2011): «La sostenibilidad del modelo turístico español en un escenario de cambio global», en Papeles de economía española, 128, 38-52.

RIPOLL BERENGUER, M.J. (2009): Pressions i conflictes territorials en el litoral mediterráni: La Marina Alta. Alicante. Instituto Alicantino de Cultura Juan Gil-Albert.

ROMERO, J. (2010): «Construcción residencial y gobierno del territorio en España. De la burbuja especulativa a la recesión. Causas y consecuencias», en Cuadernos Geográficos, 47, 17-46. Disponible en http://www.ugr.es/ cuadgeo/docs/articulos/047/047-002.pdf.

SANTAMARINA CAMPOS, B. (2008): «Patrimonialización de la naturaleza en la Comunidad Valenciana. Espacios, ironías y contradicciones», en Patrimonialización de la naturaleza. El marco social de las políticas ambientales (Beltrán, O., Pascual, J.J. y Vaccaro, I., coords.). ANKULEGI antropologia elkartea, pp. 27-44. Disponible en http://www. ankulegi.org/9-patrimonializacion-de-la-naturaleza-el-marco-social-de-las-politicasambientales/

SANTOS PAVÓN, E.L. y FERNÁNDEZ TABALES, A. (2010): «El litoral turístico español en la encrucijada: entre la renovación y el continuismo», en Cuadernos de turismo, 25, 185-206. Disponible en http://revistas.um.es/turismo/article/view/109631/104211.

SUCH CLIMENT, M.P. (1995): Turismo y medio ambiente en el litoral alicantino. Alicante. Instituto de Estudios Juan Gil-Albert.

TORRES ALFOSEA, F. (1995): Aplicación de un sistema de información geográfica al estudio de un modelo de desarrollo local. Crecimiento urbano-turístico de Torrevieja (1956-1993). Alicante. Universidad de Alicante

TORRES ALFOSEA, F. (1997): Ordenación del litoral en la Costa Blanca. Alicante. Publicaciones de la Universidad de Alicante.

VERA REBOLLO, J.F. (1984): «Mutaciones espaciales producidas por el turismo en el municipio de Torrevieja». Investigaciones Geográficas, $\mathrm{n}^{\circ}$ 2, 115-138.

VERA REBOLLO, J.F. (1987). Turismo y urbanización en el litoral alicantino. Alicante. Universidad de Alicante.

VERA REBOLLO, J.F. y BAÑOS CASTIÑEIRA, C. (2001): «Actividades y espacios turísticos», en ROMERO J., MORALES, A., SALOM, J. y VERA, F. (Coord.): La periferia emergente. La Comunidad Valenciana en la Europa de las regiones. Barcelona: Ariel Geografía, pp. 373-395. 
VERA REBOLLO, J.F. y MARCHENA, M. (1996): «El modelo turístico español: perspectiva económica y territorial», en PEDREÑO, A. (Dir.): Introducción a la economía del turismo en España. Madrid, Civitas, pp. 327-364.

VV.AA. (1990): Apéndice a la guía de la naturaleza de la Comunidad Valenciana. Parques y parajes naturales. Editorial Prensa Alicantina.

\section{Instrumentos de planificación y gestión}

AYTO. DE DÉNIA (2007): Plan general transitorio. Texto refundido. 76 pp.

AYTO. DE DÉNIA (2007): Plan general transitorio. Normas urbanísticas. 133 pp.

AYTO. DE DÉNIA (2010): Plan General. Memoria informativa. 42 pp.

AYTO. DE DÉNIA (2013): Concierto previo - Plan General de Dénia. 366 pp.

AYTO. DE JÁVEA (2010): Documento consultivo del plan general.

AYTO. DE JÁVEA (2012): Revisió i adaptació del pla general d'ordenació urbana. Text refòs. Ordenances. $240 \mathrm{pp}$.

AYTO. DE JÁVEA (2013): Pla general de Xàbia. Documento refundido. Ordenances. $190 \mathrm{pp}$.

AYTO. DE TORREVIEJA (2000): Plan general de ordenación urbana. 106 pp.

\section{Legislación y normativa}

Ley 15/1975, de 2 de mayo, de Espacios Naturales Protegidos. Boletín Oficial del Estado, 5 de mayo de $1975, \mathrm{n}^{\circ} .107$.

Decreto 25/1987, de 16 de marzo, del Consell de la Generalitat Valenciana, de declaración del Parque Natural de El Montgó. Diari Oficial de la Comunitat Valenciana, 30 de marzo de $1987, \mathrm{n}^{\circ} .556$.

Ley 5/1988, de 24 de junio, de la Generalitat Valenciana, por la que se regulan los Parajes Naturales de la Comunidad Valenciana. Diari Oficial de la Comunitat Valenciana, de 2 de julio de $1988, n^{\circ} .859$.

Ley 22/1988, de 28 de julio, de Costas. Boletín Oficial del Estado, 29 de julio de 1988, $\mathrm{n}^{\circ}$. 181.

Ley 11/1994, de 27 de diciembre, de la Generalitat Valenciana, de Espacios Naturales Protegidos de la Comunidad Valenciana. Diari Oficial de la Comunitat Valenciana, de 9 de enero de $1995, \mathrm{n}^{\circ} .2423$.

Decreto 237/1996, de 10 de diciembre, del Gobierno valenciano, de declaración del parque natural de las Lagunas de la Mata y Torrevieja. Diari Oficial de la Comunitat Valenciana, 18 de diciembre de $1996, \mathrm{n}^{\circ} .2892$.

Decreto 180/2002, de 5 de noviembre, del Gobierno Valenciano, por el que se aprueba el Plan de Ordenación de los Recursos Naturales del Montgó. Diari Oficial de la Comunitat Valenciana, de 8 de noviembre de 2002, $\mathrm{n}^{\circ} .4374$.

Decreto 11/2007, de 26 de enero, del Consell, por el que se suspende parcialmente la vigencia del Plan General de Jávea. Diari Oficial de la Comunitat Valenciana, de 29 de enero de $2007, n^{\circ} .5438$. 
Decreto 31/2010, de 12 de febrero del Consell, por el que se aprueba el Plan de Ordenación de Recursos Naturales del Sistema de Zonas Húmedas del Sur de Alicante. Diari Oficial de la Comunitat Valenciana, 16 de febrero de 2010, $\mathrm{n}^{\circ} .6207$.

Decreto 41/2010, de 5 de marzo, del Consell, por el que se aprueba el Plan Rector de Uso y Gestión del Parque Natural de las Salinas de Santa Pola. Diari Oficial de la Comunitat Valenciana, 09 de marzo de 2010, núm. 6222.

Decreto 54/2013, de 26 de abril, del Consell, por el que, de conformidad con lo establecido en el art. 102 de la Ley Urbanística Valenciana, se suspende la vigencia del Plan General de Ordenación Urbana de Denia de 1972 y se establece el régimen urbanístico transitoriamente aplicable en tanto culmine el procedimiento de aprobación del plan general en trámite. Diari Oficial de la Comunitat Valenciana, 3 de mayo de 2013, nº 7016.

\section{Índice de siglas y acrónimos}

ENP: Espacio(s) natural(es) protegido(s).

IVE: Instituto Valenciano de Estadística.

LIC: Lugar de importancia comunitaria.

PAI: Plan de Actuación Integrada.

PGOU: Plan General de Ordenación Urbana.

PGT: Plan General Transitorio.

PN: Parque natural.

PORN: Plan de ordenación de los recurso naturales.

SNU: Suelo no urbanizable.

SNUEP: Suelo no urbanizable de especial protección.

SNUP: Suelo no urbanizable de protección.

SRIT: Suelo rústico de interés turístico.

SZHSA: Sistema de zonas húmedas del sur de Alicante.

TS: Tribunal Supremo.

TSJCV: Tribunal Superior de Justicia de la Comunidad Valenciana.

ZEPA: Zona de especial protección para las aves. 
